\title{
Efeito da deriva simulada de glyphosate em diferentes partes da planta de Eucalyptus grandis
}

\section{Simulated drift effect of glyphosate in different parts of Eucalyptus grandis plants}

\author{
Andreia Cristina Peres Rodrigues da $\operatorname{Costa}^{1}$; Neumárcio Vilanova da $\operatorname{Costa}^{2 *}$; \\ Maria Renata Rocha Pereira ${ }^{3}$; Dagoberto Martins ${ }^{4}$
}

\begin{abstract}
Resumo
No presente trabalho objetivou-se avaliar os efeitos da deriva simulada de glyphoste em plantas de Eucalyptus grandis, por meio da aplicação de doses reduzidas em diferentes partes da planta. Utilizouse o delineamento inteiramente casualizado, com cinco repetições. Os tratamentos foram constituídos da aplicação de 0; 30; 60; 90 e 120 g e.a.ha ${ }^{-1}$ de glyphosate, da formulação comercial Scout $\AA$. A aplicação foi realizada de três formas: aplicação sobre as folhas, no caule e na planta inteira (folha + caule). Para a aplicação nas folhas o caule foi coberto com fitas plásticas para evitar que fosse atingido pela solução, e o mesmo foi feito com as plantas que receberam pulverização no caule, cobrindo as folhas com saco plástico. A aplicação foi realizada em um pulverizador estacionário, munido de pontas XR 11002 VS, com pressão de $183 \mathrm{KPa}$ e com consumo de calda de $200 \mathrm{~L} \mathrm{ha}^{-1}$. As plantas de eucalipto que receberam aplicações nas folhas e na planta inteira (folhas + caule) apresentaram efeitos de intoxicação mais intenso em relação às plantas que receberam aplicações somente no caule. Entretanto, pode ocorrer incrementos no crescimento em altura e na massa seca total das plantas de eucalipto em aplicações da dose de 30 g e.a. ha ${ }^{-1}$ de glyphosate.
\end{abstract}

Palavras-chave: Eucalipto, herbicida, subdose

\begin{abstract}
The present work aimed to evaluate the effects of simulated drift of glyphoste on Eucalyptus grandis, through the application of low doses in different parts of the plant. The experimental design was a randomized block design with five replications. The treatments were glyphosate application at $0 ; 30$; 60; 90 e $120 \mathrm{~g}$ a.e. ha ${ }^{-1}$ of the commercial formulation Scout ${ }^{\circledR}$. Three forms of application were used: applying on leaf, on stem, and on the entire plant (leaf + stem). For leaf application, stems were covered with plastic ribbons to protect them from the solution; the same was made with plants that were sprayed on stems, covering leaf with plastic bag. The application was carried out in an armed stationary spray tips XR 11002 VS, with $183 \mathrm{KPa}$ pressure in volume of $200 \mathrm{~L} \mathrm{ha}^{-1}$. The eucalyptus plants receiving applications in leaves and whole plant (leaves + stem) showing effects of intoxication are more intense about the plants that received the stem applications only. However, there may be increases in height growth and total dry mass of eucalyptus plants in applications of $30 \mathrm{~g}$ a.e. $\mathrm{ha}^{-1}$ glyphosate.
\end{abstract}

Key words: Eucalyptus, herbicide, simulated drift

\footnotetext{
1 Pós-Doutoranda da Universidade Estadual do Oeste do Paraná, UNIOESTE, Marechal Cândido Rondon, PR. E-mail: andreiacpr@ hotmail.com

2 Prof. Adjunto da UNIOESTE, Marechal Cândido Rondon, PR. E-mail: neumarcio.costa@unioeste.br

3 Pós-Doutoranda da Universidade Estadual Paulista, FCA, UNESP, Botucatu, SP. E-mail: mariarenata10@hotmail.com

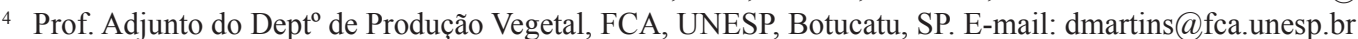

* Autor para correspondência
} 


\section{Introdução}

O eucalipto destaca-se dentre as espécies florestais mais utilizadas no Brasil, devido ao rápido crescimento e boa adaptação às condições solo e clima das regiões do país. Apesar de o gênero Eucalyptus apresentar espécies de rápido crescimento e de boa competitividade quanto ao seu estabelecimento no campo, isso não o isenta da interferência das plantas daninhas, tendo como conseqüência o decréscimo quantitativo e qualitativo da sua produção. Esse fato coloca as plantas daninhas como um grande problema para implantação, manutenção e reforma de florestas de eucalipto, o que tem fomentado o interesse de vários pesquisadores nas últimas décadas. (SANTOS et al., 2005; 2006a, 2006b, 2006c; 2007; 2008; 2009; AGOSTINETTO et al., 2010; MACHADO et al., 2010).

Entre as justificativas para preocupação com o controle de plantas daninhas estão os prejuízos ao crescimento, causados pela competição por luz, nutrientes e água, e o fato de exercerem interferência de natureza alelopática, além de aumentar riscos de incêndio e dificultar os demais tratos silviculturais (PITELLI, 1987; PITELLI; MARCHI, 1991). Desta forma, o método químico para o controle das plantas daninhas vem sendo amplamente utilizado e difundido.

Dentre os herbicidas utilizados na eucaliptocultura, destaca-se o glyphosate, que apresenta ação sistêmica, amplo espectro de controle e inibidor da enzima 5-enolpiruvil shiquimato3-fosfato sintetase (EPSP sintetase) que impede a formação dos aminoácidos aromáticos fenilalanina, tirosina e triptofano (RODRIGUES; ALMEIDA, 2005).

O controle das plantas daninhas com glyphosate, em aplicações dirigidas, é intenso nos dois primeiros anos de implantação da cultura, podendo, em caso de reinfestação, estender-se por quase todo o ciclo por questões operacionais e busca de incrementos na produtividade. Contudo, em áreas em que o glyphosate vem sendo freqüentemente utilizado no controle de plantas daninhas em reflorestamento de eucalipto são observados sintomas de intoxicação, em intensidades variáveis, devido à deriva (SANTOS et al., 2005; 2006a, 2006c; 2007; 2008).

Ressalta-se que mesmo em aplicações dirigidas do glyphosate é difícil evitar a deriva de gotas para o caule e as folhas das plantas de eucalipto, além de que, o efeito fitotóxico da deriva está relacionado à quantidade de ingrediente ativo que é absorvido pela planta. Contudo, existem na literatura poucas informações referentes ao nível de tolerância a subdoses e os pontos preferenciais de absorção do glyphosate em plantas de eucalipto.

Desta forma, o presente trabalho teve como objetivo avaliar os efeitos da deriva simulada de glyphoste em plantas de Eucalyptus grandis, por meio da aplicação de doses reduzidas em diferentes partes da planta.

\section{Material e Métodos}

O estudo foi conduzido em casa de vegetação, na Fazenda Experimental Lageado, pertencente à Faculdade de Ciências Agronômicas/UNESP, campus de Botucatu/SP, entre os meses de junho e julho de 2007. Mudas padronizadas de Eucalyptus grandis, oriundas de semente, com quatro meses de idade, foram plantadas em vasos preenchidos com 7 litros de volume de solo. O solo utilizado foi classificado de acordo com o novo Sistema Brasileiro de Classificação de Solos (EMBRAPA, 1999) e denominado de Latossolo Vermelho Distróférrico típico de textura argilosa $(50,4 \%$ de argila, $25,7 \%$ de silte e $23,9 \%$ de areia). Este foi seco à sombra, peneirado em malha de $5 \mathrm{~mm}$ e a adubação para o plantio foi realizada de acordo com a análise química do solo (Tabela 1), utilizando a recomendação de $30 \mathrm{~kg} \mathrm{ha}^{-1}$ de N, $60 \mathrm{~kg} \mathrm{ha}^{-1}$ de P e $30 \mathrm{~kg} \mathrm{ha}^{-1}$ de K.

Utilizou-se o delineamento fatorial $3 \times 5$, correspondente a três locais de aplicação e cinco 
doses de glyphosate, com cinco repetições. Em cada vaso apenas uma muda de E. grandis foi conduzida. Foram utilizadas as seguintes doses de glyphosate da formulação comercial Scout ${ }^{\circledR} 0 ; 30 ; 60 ; 90$ e 120 g e.a. ha- ${ }^{-1}$, simulando uma deriva.

Os três locais de aplicação foram: aplicação sobre as folhas, o caule e planta inteira (folha + caule). Para a aplicação nas folhas, o caule foi coberto com fitas plásticas para evitar o contato com o jato de pulverização do herbicida, o mesmo foi feito com as plantas que receberam pulverização no caule, no qual se cobriu as folhas com saco plástico. A aplicação foi realizada em um pulverizador estacionário munido de 4 pontas XR 11002 VS, com pressão de $183 \mathrm{KPa}$ e volume de calda correspondente a $200 \mathrm{~L} \mathrm{ha}^{-1}$. A aplicação foi realizada dia 14/06/2007, quando as plantas apresentaram altura média de $30 \mathrm{~cm}$.

Tabela 1. Análise química de fertilidade do solo utilizado no experimento. Botucatu/SP, 2007.

\begin{tabular}{|c|c|c|c|c|c|c|c|c|}
\hline \multirow{2}{*}{$\begin{array}{c}\mathrm{PH} \\
\mathrm{CaCl}_{2}\end{array}$} & \multirow{2}{*}{$\begin{array}{l}\text { M.O. } \\
\mathrm{g} \mathrm{dm}^{-3}\end{array}$} & \multirow{2}{*}{$\begin{array}{l}\text { P resina } \\
\mathbf{m g ~ d m}^{-3}\end{array}$} & \multicolumn{5}{|c|}{$\mathrm{mmol} \mathrm{dm}^{-3}$} & \multirow{2}{*}{$V(\%)$} \\
\hline & & & $\mathbf{H}+\mathbf{A l}$ & $\mathbf{K}$ & $\mathbf{M g}$ & SB & CTC & \\
\hline 5,2 & 24 & 34 & 5,3 & 28 & 19 & 53 & 87 & 61 \\
\hline
\end{tabular}

Fonte: Elaboração dos autores.

No momento da aplicação a umidade relativa do ar encontrava-se a $93 \%$ e a temperatura do ar a $19^{\circ} \mathrm{C}$. Aos $0,7,14,21$ e 28 dias após a aplicação (DAA), foram mensurados a altura das plantas (região entre o coleto e o ápice) e o diâmetro do caule a $1 \mathrm{~cm}$ do solo. Subtraindo-se a altura e o diâmetro mesurados aos 28 DAA pelos valores do dia da simulação da deriva, obteve-se o crescimento em altura $(\mathrm{cm})$ e diâmetro $(\mathrm{mm})$ por planta após a exposição ao glyphosate. Aos 7, 14, 21 e 28 DAA, determinou-se a porcentagem de intoxicação das plantas em relação à testemunha, por meio de uma escala de notas, no qual $0 \%$ corresponde à ausência de sintomas visíveis e $100 \%$ à morte das plantas segundo a SBCPD (1995).

Aos 28 DAA, foi determinada a área foliar $\left(\mathrm{cm}^{2}\right)$ das plantas por meio do medidor "Area Meter" (modelo LICOR LI-3000) e a parte aérea e as raízes foram acondicionadas em sacos de papel sendo mantida em estufa de ventilação forçada de ar para secagem por 72 horas a temperatura de $60^{\circ} \mathrm{C}$ e em seguida pesadas para a determinação da massa seca total.

Os dados obtidos foram submetidos ao teste de normalidade e análises de regressão que apresentaram explicação biológica e elevado $\mathrm{R}^{2}$, utilizando-se o programa SigmaStat 2.0.

\section{Resultados e Discussão}

Na Figura 1, pode-se observar que os sintomas visuais de intoxicação do glyphosate foram verificados até o final das avaliações, aos 28 após aplicação (DAA), exceto para as aplicações no caule. A partir dos 7 DAA verificou-se sintomas de intoxicação superior a 10\% nas plantas que receberam a dose de glyphosate a partir de $90 \mathrm{~g}$ e.a. $\mathrm{ha}^{-1}$, nas folhas e na planta inteira (folhas + caule) (Figura 1-A).

Os sintomas visuais de intoxicação, quando observados, eram compostos por cloroses e necroses foliares, sendo que as plantas com maior intensidade de intoxicação apresentavam clorose e morte dos ápices caulinares. Sintomas semelhantes também foram verificados em Eucalyptus grandis, E. urophylla, E. urograndis, E. saligna, E. pellita e E. resinifera por Santos et al. 2006a, 2006b; 2007. A clorose pode ser resultado da degeneração dos cloroplastos (CAMPBELL; EVANS; REED, 1976) e/ou da inibição da formação de clorofila (COLE; CASELEY; DODGE, 1983) em plantas tratadas com glyphosate. 
Figura 1. Porcentagem de intoxicação de plantas de Eucalyptus grandis após a deriva simulada de glyphosate em três locais de aplicação: folha, caule e planta inteira (folha + caule), avaliado aos 7 (A), 14 (B), 21 (C) e 28 (D) dias após a aplicação. Botucatu/SP, 2007.

A

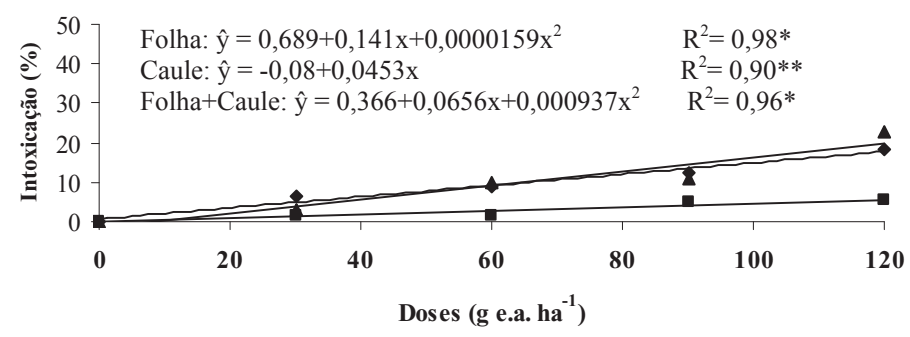

- Folha Caule $\Delta$ Folha + Caule

B

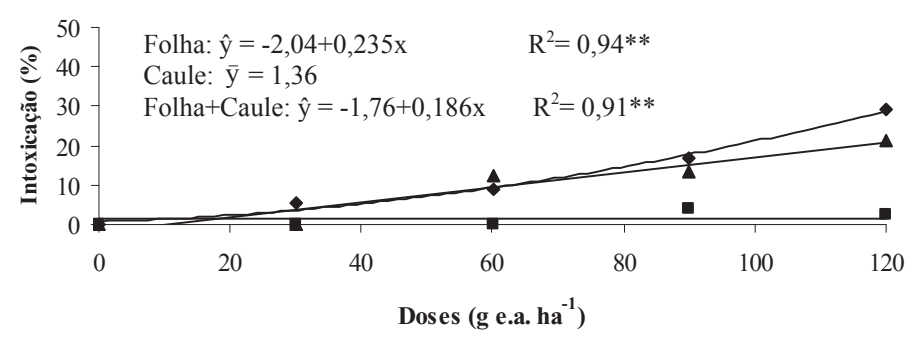

- Folha - Caule $\Delta$ Folha + Caule

C

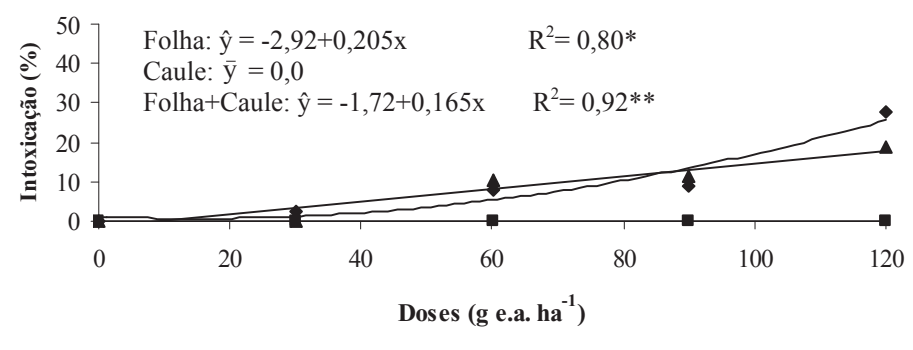

- Folha - Caule $\Delta$ Folha + Caule

D

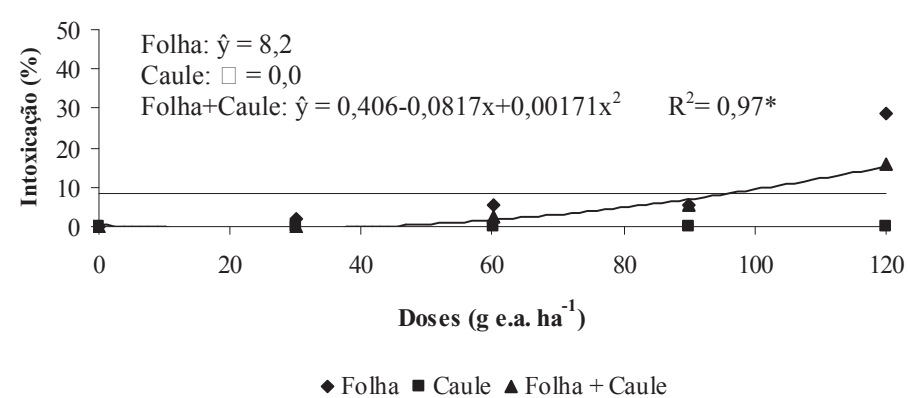

Fonte: Elaboração dos autores. 
Santos et al. (2005), trabalhando com simulação de deriva em clones de eucalipto (E. urophylla $\mathrm{x}$ E. grandis), observaram que o aparecimento dos sintomas relacionava-se à quantidade de produto em contato com as plantas e que os sintomas eram observados já a partir do quinto dia após aplicação e que houve recuperação das plantas tratadas com a dose de 172,8 g e.a. ha-1 de glyphosate após os 45 DAA com emissão de novas brotações, porém com sintomas de intoxicação nas folhas mais velhas.

Aos 14 DAA, as plantas que receberam as aplicações nas folhas e na planta inteira (folha + caule) apresentaram maior intoxicação 8,8 e 12,4\%, respectivamente, a partir da dose de $60 \mathrm{~g}$ e.a. ha ${ }^{-1}$ de glyphosate, em relação às aplicações no caule (Figura 1-B). Comportamento semelhante foi observado aos 21 DAA (Figura 1-C). As plantas de eucalipto em que os tratamentos foram aplicados sobre a planta inteira (folhas + caule) apresentaram sintomas de maior intensidade, tendo parte delas recuperadas aos 28 DAA, exceto para as plantas que receberam a maior dose (120 g e.a. ha-1), que apresentaram maior porcentagem de intoxicação e morte do ápice das plantas (Figura 1-D).

Santos et al. (2006a), verificaram em plantas de E. grandis, E. urophylla, E. saligna, E. pellita e E. resinifera que a deriva de 43,2 g e.a. ha ${ }^{-1}$ de glyphosate, proporcionou médias de intoxicação inferior a 5,5\% aos $45 \mathrm{DAA}$, enquanto que a deriva do dobro da dose causou $27,8 \%$ de intoxicação no mesmo período. Resultados semelhantes também foram obtidos por Santos et al. (2008), Machado et al. (2010) e Pereira et al. (2011).

Pereira et al. (2011), avaliando a deriva simulada de glyphosate em E. grandis, observaram que nas doses de 160 e 240 g e.a. ha-1, o caule pode absorver e translocar maior quantidade de glyphosate para o resto da planta do que as folhas, devido à ação do produto, que interrompe o ciclo do carbono no cloroplasto, causando redução na síntese de carboidratos, diminuindo o transporte destes para os drenos e, consequentemente, diminuindo o transporte de glyphosate (MCALLISTER;
HADERLIE, 1985), uma vez que ocorreu menor taxa de distribuição do produto quando este foi aplicado somente na folha.

$\mathrm{Na}$ Figura 2, estão apresentados as curvas de regressão para os dados de altura de plantas de $E$. grandis após a deriva simulada de glyphosate em três locais de aplicação folha, caule e planta inteira (folha + caule), aos 28 dias após a aplicação. Houve ajuste apenas para os dados das plantas que receberam a aplicação nas folhas, sendo que a redução no crescimento em altura das plantas foi em torno de 42,6 e $100,0 \%$, quando se utilizou as doses de 90 e 120 g e.a. ha ${ }^{-1}$, respectivamente. O crescimento nulo, observado nas plantas que receberam a maior dose de glyphosate foi devido à morte do ápice caulinar, em conseqüência da maior porcentagem de intoxicação apresentados pelas plantas. Entretanto, ocorreu aumento no crescimento em altura de $8,8 \%$, na dose de 30 g e.a. ha ${ }^{-1}$.

Velini et al. (2008) ressaltam que o glyphosate aplicado em altas doses inibiu o crescimento de espécies não transgênicas, como Glycine max, Zea mays, Commelina benghalensis, Eucalyptus grandis e Pinus caribea. Entretanto, quando aplicado em doses baixas (1,8 a 36,0 g e.a. ha- $\left.{ }^{-1}\right)$, o glyphosate proporcionou estímulo entre 50 e $100 \%$ no crescimento de folha, caule e raiz, nas espécies $C$. benghalensis, E. grandis e P. caribea. Da mesma forma, Cedergreen (2008) afirma que o glyphosate pode estimular o acúmulo de biomassa em plantas de Hordeum vulgare em torno de $25 \%$, quando são aplicadas doses que correspondem de 5 a $10 \%$ da dose recomendada. Contudo, o processo que explica a ação do glyphosate como regulador vegetal em baixas doses ainda não foi elucidado.

Na Figura 3, pode-se verificar que os dados de diâmetro do caule apresentaram ajuste apenas para as plantas que receberam aplicações na planta inteira (folhas + caule). Desta maneira, houve redução no crescimento do diâmetro do caule em cerca de $25,0 \%$, quando utilizou-se as doses de 30 e $60 \mathrm{~g}$ e.a. $\mathrm{ha}^{-1}$, sendo que para as doses de 90 e $120 \mathrm{~g}$ e.a. ha ${ }^{-1}$ a redução foi de $37,5 \%$ para ambas as doses. 
Figura 2. Crescimento em altura de plantas de Eucalyptus grandis após a deriva simulada de glyphosate em três locais de aplicação folha, caule e planta inteira (folha + caule), aos 28 dias após a aplicação. Botucatu/SP, 2007.

Folha: $\hat{y}=13,606+0,0936 x-0,00173 x^{2} \quad R^{2}=0,99 * *$

Caule: $\overline{\mathrm{y}}=13,88$

Folha+Caule: $\bar{y}=10,16$

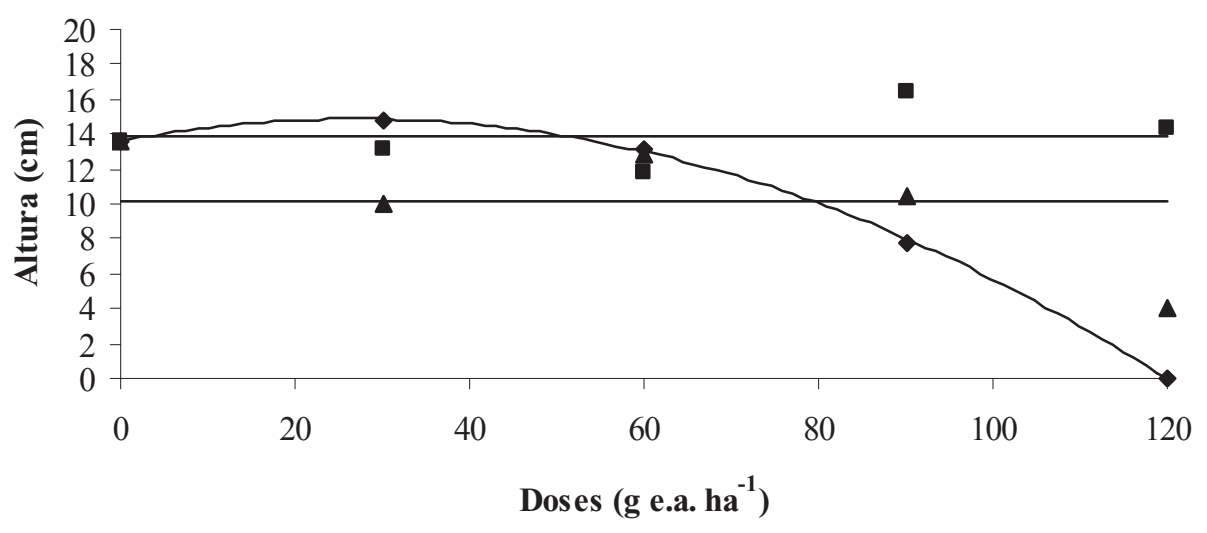

- Folha - Caule $\Delta$ Folha + Caule

Fonte: Elaboração dos autores.

Figura 3. Crescimento do diâmetro do caule de plantas de Eucalyptus grandis após a deriva simulada de glyphosate em três locais de aplicação folha, caule e planta inteira (folha + caule), aos 28 dias após a aplicação. Botucatu/SP, 2007.

Folha: $\overline{\mathrm{y}}=2,44$

Caule: $\overline{\mathrm{y}}=2,96$

Folha+Caule: $\hat{y}=3,197 / 1+(x / 319,932)^{0,513} \quad R^{2}=0,96^{*}$

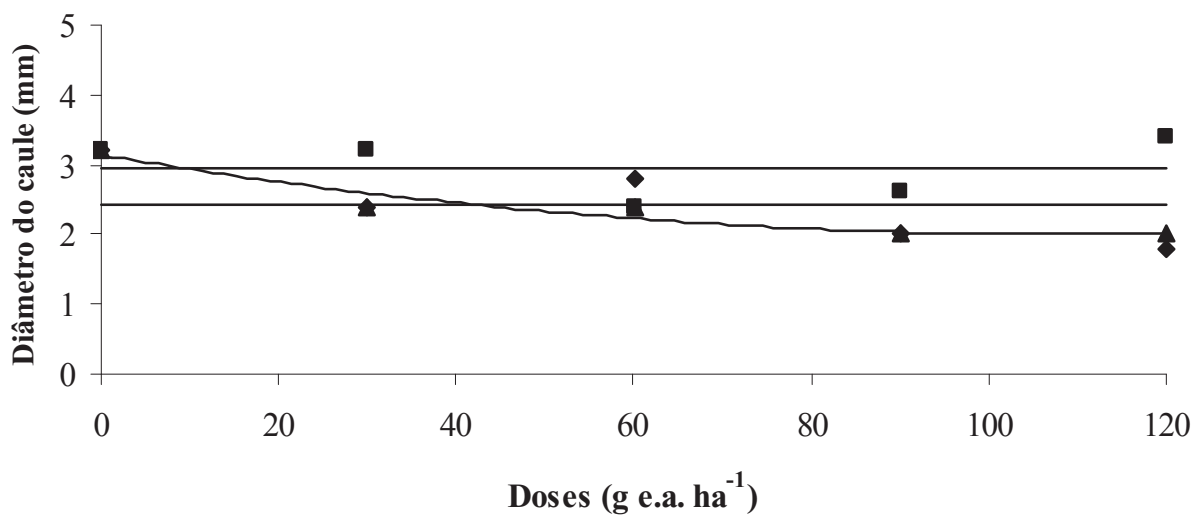

- Folha — Caule \ Folha + Caule

Fonte: Elaboração dos autores. 
Para os dados de área foliar das plantas de eucalipto houve ajuste apenas para os dados das plantas que receberam a aplicação nas folhas (Figura 4). Verificaram-se decréscimos de 26,1; 60,8 e $57,6 \%$ da área foliar com a aplicação das doses de 60, 90 e 120 g e.a. ha ${ }^{-1}$ de glyphosate, respectivamente. Enquanto que, na dose de $30 \mathrm{~g}$ e.a. ha ${ }^{-1}$ ocorreu um incremento na área foliar de $22,9 \%$, semelhante ao observado para o crescimento em altura das plantas.

Figura 4. Área foliar de plantas de Eucalyptus grandis após a deriva simulada de glyphosate em três locais de aplicação folha, caule e planta inteira (folha + caule), aos 28 dias após a aplicação. Botucatu/SP, 2007.

Folha: $\hat{y}=967,252-4,634 x \quad R^{2}=0,75^{* *}$

Caule: $\bar{y}=825,42$

Folha+Caule: $\bar{y}=788,42$

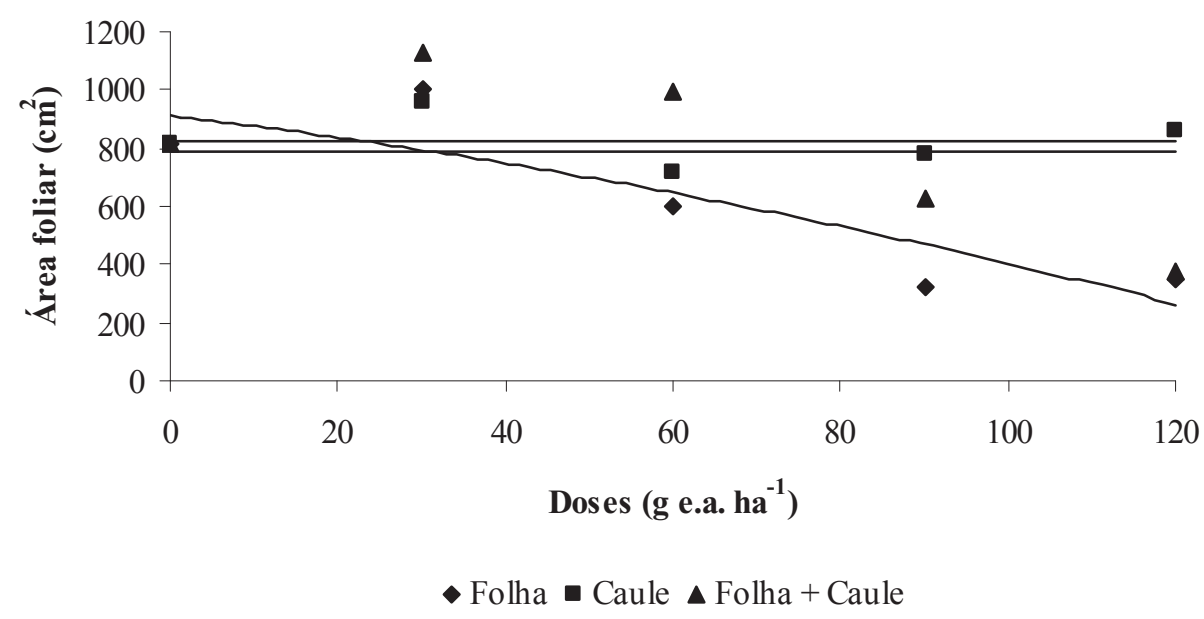

Fonte: Elaboração dos autores.

Na Figura 5, estão apresentados os ajustes dos dados de massa seca total de plantas de Eucalyptus grandis após a deriva simulada de glyphosate em três locais de aplicação folha, caule e planta inteira (folha + caule), aos 28 dias após a aplicação. Não houve ajuste apenas os dados das plantas que receberam a aplicação no caule, contudo, para as plantas que receberam aplicações na planta inteira (folhas + caule) ocorreu redução da massa seca das plantas em cerca de $25,0 \%$ a partir da utilização da dose de 30 g e.a. ha-1 ${ }^{-1}$ atingindo o máximo de 55,6\% na maior dose utilizada (120 g e.a. ha-1).

Paraas plantasquereceberamaplicaçãonas folhas, houve redução de massa seca de 13,9; 44,4 e 55,6\% nas doses de 60, 90 e 120 g e.a. ha-1 de glyphosate, respectivamente. Sendo que, para a dose de 30 g e.a. ha-1 ocorreu um aumento da massa seca das plantas de $11,1 \%$, evidenciando que o glyphosate em doses reduzidas pode induzir a um aumento do crescimento e da área foliar de plantas de eucalipto, agindo como um regulador vegetal, sendo que com este aumento de área foliar a planta poderá apresentar maior área fotossintética o que possibilitará talvez maior crescimento e desenvolvimento.

Machado et al. (2010), observaram que na simulação de deriva em plantas de eucalipto das doses de 43,2 e 86,4 g e.a. ha ${ }^{-1}$ de glyphosate, houve incremento na produção de massa seca por unidade de água transpirada. Entretanto, a partir da dose de 86,4 g e.a. ha-1 de glyphosate ocorreu redução na 
eficiência no uso da água pelas plantas. Da mesma maneira, Pereira et al. (2010) verificaram em E. grandis que as características fisiológicas não foram influenciadas quando a aplicação do glyphosate foi realizada somente nas folhas ou no caule, independente da dose utilizada (30 a 120 g e.a. ha $\left.^{-1}\right)$. Entretanto, quando a aplicação foi realizada na planta inteira, houve redução na transpiração, aumento da resistência estomática e da temperatura foliar, a partir da aplicação de $60 \mathrm{~g}$ e.a. ha- $\mathrm{h}^{-1}$, enquanto que na dose de 30 g e.a. ha-1, ocorreu diminuição da resistência estomática e consquente aumento da transpiração e redução na temperatura das folhas.

Figura 5. Massa seca total de plantas de Eucalyptus grandis após a deriva simulada de glyphosate em três locais de aplicação folha, caule e planta inteira (folha + caule), aos 28 dias após a aplicação. Botucatu/SP, 2007.

$$
\begin{array}{ll}
\text { Folha: } \hat{\mathrm{y}}=7,673 / 1+(\mathrm{x} / 99,958)^{2,789} & \mathrm{R}^{2}=0,95 * \\
\text { Caule: } \overline{\mathrm{y}}=13,88 & \\
\text { Folha+Caule: } \hat{\mathrm{y}}=7,00-00273 \mathrm{x} & \mathrm{R}^{2}=0,81^{*}
\end{array}
$$

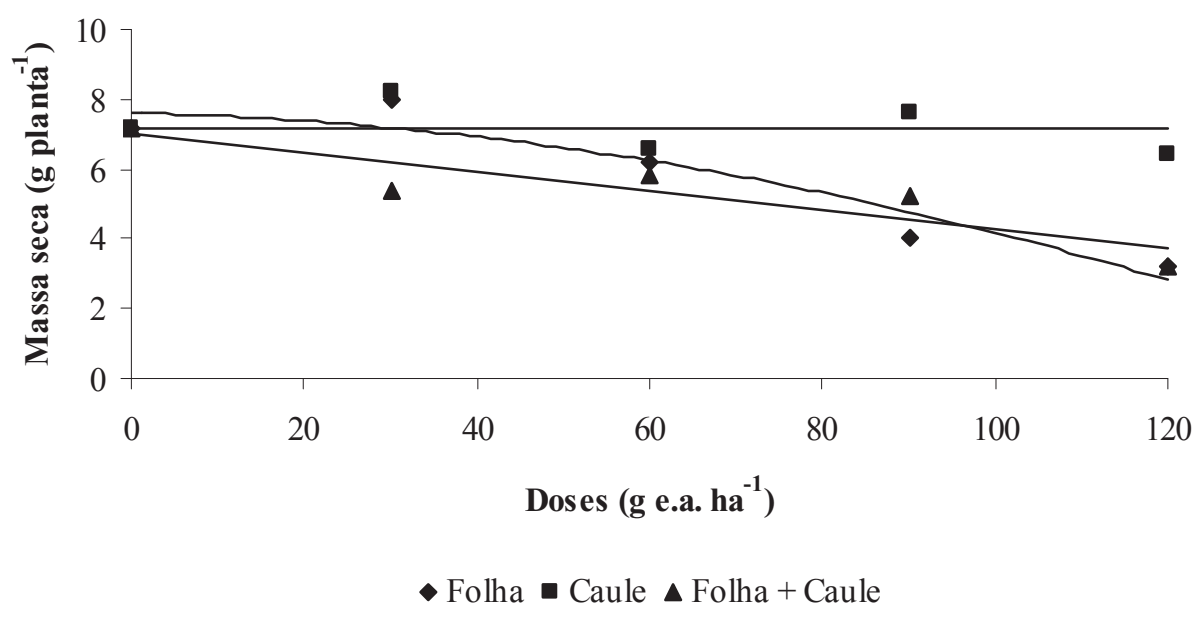

Fonte: Elaboração dos autores.

De acordo com Santos et al. (2006a), plantas de eucalipto apresentaram redução na altura, diâmetro e massa seca, quando submetidas doses de glyphosate de 172,8 e 345,6 g e.a. ha $^{-1}$, ocasionados pelas injúrias severas que levaram à morte dos ponteiros, senescência foliar e, conseqüentemente, ao comprometimento do crescimento. Contudo, os autores citam que a espécie E. resinifera, na dose de 86,4 g e.a. ha ${ }^{-1}$ apresentou comportamento semelhante ao de plantas não expostas ao herbicida.

Santosetal.(2007), citamque ocomprometimento no crescimento de clones de eucalipto foi constatado em plantas com intoxicação inicial acima de $21 \%$; entretanto, deve-se atentar para intoxicações inferiores, que podem ser prejudiciais em genótipos mais sensíveis ao glyphosate. Contudo, a diferença de tolerância entre espécies e entre clones pode ser usada na escolha de materiais genéticos a serem cultivados, constituindo-se em informação relevante para o manejo da cultura (SANTOS et al., 2006a; 2007).

Desta forma, deve-se atentar para os cuidados a serem tomados com a tecnologia de aplicação de herbicidas e com as doses recomendadas no 
controle de plantas daninhas na eucaliptocultura (SANTOS et al., 2006a), sendo necessário estudos sobre tipos de pontas de pulverização utilizada, bem como volume de calda de aplicação, que possam fornecer subsídios para um melhor aproveitamento do herbicida aplicado e uma menor deriva.

\section{Conclusões}

Com base nos resultados obtidos pode-se concluir que houve prejuízos da deriva de glyphosate no crescimento de eucalipto, sendo que, os maiores danos as plantas ocorreram quando a simulação da deriva foi realizada nas folhas e na planta inteira (folhas + caule), além de que a deriva apenas no caule pode ser desprezada.

Contudo, pode ocorrer aumento no crescimento em altura e na massa seca total das plantas de eucalipto em aplicações da dose de 30 g e.a. ha-1 de glyphosate.

\section{Referências}

AGOSTINETTO, D.; TAROUCO, C. P; MARKUS, C.; OLIVEIRA, E.; SILVA, J. M. B. V.; TIRONI, S. P. Seletividade de genótipos de eucalipto a doses de herbicidas. Semina: Ciências Agrárias, Londrina, v. 31, n. 3, p. 585-598, 2010.

CAMPBELL, W. F.; EVANS, J. O.; REED, F. C. Effect of glyphosate on chloroplast ultrastructure of quack grass mesophyll cell. Weed Science, Champaign, v. 24, p. 2225, 1976.

CEDERGREEN, N. Herbicides can stimulate plant growth. Weed Research, Oxford, v. 48, n. 5, p. 429-438, 2008.

COLE, D. J.; CASELEY, J. C.; DODGE, A. D. Influence of glyphosate on selected plant process. Weed Research, Oxford, v. 23, p. 173-183, 1983.

EMPRESA BRASILEIRA DE PESQUISA AGROPECUÁRIA - EMBRAPA. Centro Nacional de Pesquisa de Solos. Sistema brasileiro de classificação de solos. Rio de Janeiro: Embrapa, 1999. 412 p.

MACHADO, A. F. L.; FERREIRA, L. R.; SANTOS, L. D. T.; FERREIRA, F. A.; VIANA, R. G.; MACHADO, M. S.; FREITAS, F. C. L. Eficiência fotossintética e uso da água em plantas de eucalipto pulverizadas com glyphosate. Planta Daninha, Viçosa, MG, v. 28, n. 2, p. 319-327, 2010.

MCALLISTER, R.; HABERLIE, L.L. Translocation of 14C-Glyphosate and 14CO2 - Labeled photoasimilates in Canada thistle (Cirsium arvense). Weed Science, Champaign, v. 33, p. 153-159, 1985.

PEREIRA, M. R. R.; RODRIGUES, A. C. P.; COSTA, N. V. C.; MARTINS, D.; KLAR, A. E.; SILVA, M. R. Efeito da deriva de glyphosate sobre algumas características fisiológicas em plantas de eucalipto. Interciencia, Caracas, v. 35, n. 4, p. 279-283, 2010.

PEREIRA, M. R. R.; RODRIGUES, A. C. R.; CAMPOS, C. F.; FILHO, A. L. M.; MARTINS, D. Absorção de subdoses glyphosate aplicadas em diferentes locais de plantas de eucalipto. Revista Árvore, Viçosa, v. 35, n. 3 , p. 589-594, 2011.

PITELLI, R. A. Competição e controle de plantas daninhas em áreas agrícolas. IPEF, v. 4, n. 12, p. 25-35, 1987.

PITELLI, R. A.; MARCHI, S. R. Interferência das plantas invasoras nas áreas de reflorestamento. In: SEMINÁRIO TECNICO SOBRE PLANTAS DANINHAS E O USO DE HERBICIDAS EM REFLORESTAMENTO, 3., 1991, Rio de Janeiro. Anais... Rio de Janeiro: Sociedade Brasileira de Silvicultura, 1991. p. 110-123.

RODRIGUES, B. N.; ALMEIDA, F. S. Guia de herbicidas. 5. ed. Londrina: Grafmarke, 2005. 591 p.

SANTOS, L. D. T.; FERREIRA, F. A.; FERREIRA, L. R.; DUARTE, W. M.; TIBURCIO, R. A. S.; SANTOS, M. V. Intoxicação de espécies de eucalipto submetidas a deriva do glyphosate. Planta Daninha, Viçosa, MG, v. 24, n. 2, p. 359-364, 2006 a.

SANTOS, L. D. T.; FERREIRA, F. A.; MEIRA, R. M. S. A.; BARROS, N. F.; FERREIRA, L. R.; MACHADO, A. F. L. Crescimento e morfoanatomia foliar de eucalipto sob efeito de deriva do glyphosate. Planta Daninha, Viçosa, MG, v. 23, n. 1, p. 143-152, 2005.

SANTOS, L. D. T.; FERREIRA, L. R.; FERREIRA, F. A.; DUARTE, W. M.; TIBURCIO, R. A. S.; MACHADO, A. F. L. Intoxicação de eucalipto submetido à deriva simulada de diferentes herbicidas. Planta Daninha, Viçosa, MG, v. 24, n. 3, p. 521-526, 2006 c.

SANTOS, L. D.: SANT'ANNA-SANTOS, B. F.; MEIRA, R. M. S. A.; FERREIRA, F. A.; TIBURCIO, R. A. S. T.; SILVA, E. C. F. Micromorfologia foliar na análise da fitotoxidez por glyphosate em Eucalyptus grandis. Planta Daninha, Viçosa, MG, v. 27, n. 4, p. 711720, 2009. 
SANTOS, L. D.; SANT'ANNA-SANTOS, B. F.; MEIRA, R. M. S. A.; TIBURCIO, R. A. S.; FERREIRA, F. A.; MELO, C. A. D.; SILVA, E. F. S. Danos visuais e anatômicos causados pelo glyphosate em folhas de Eucalyptus grandis. Planta Daninha, Viçosa, MG, v. 26, n. 1, p. 9-16, 2008.

SANTOS, L. D. T.; IAREMA, L.; THADEO, M.; FERREIRA, F. A.; MEIRA, R. M. S. A. Características da epiderme foliar de eucalipto e seu envolvimento com a tolerância ao glyphosate. Planta Daninha, Viçosa, MG, v. 24, n. 3 , p. 513-520, 2006 b.
SANTOS, L. D. T.; MACHADO, A. F. L.; VIANA, R. G.; FERREIRA, L. R.; FERREIRA, F. A.; SOUZA, G. V. R. Crescimento do eucalipto sob efeito da deriva de glyphosate. Planta Daninha, Viçosa, MG, v. 25, n. 1, p. 133-137, 2007.

SOCIEDADE BRASILEIRA DA CIENCIA DAS PLANTAS DANINHAS - SBCPD. Procedimentos para instalação, avaliação e análise de experimentos com herbicidas. Londrina: SBCPD, 1995. 42 p.

VELINI, E. D.; ALVES, E.; GODOY, M. C.; MESCHEDE, D. K.; SOUZA, R. T.; DUKE, S. O. Glyphosate applied at low doses can stimulate plant growth. Pest Management Science, v. 64, n. 4, p. 489496, 2008. 